\title{
$\mathrm{RPS}$ 제도 시행에 따른 의무이행 현황 분석 및 개선방안 연구
}

\section{A Study on the Present State of Duty Performance According to the RPS System and Improvement Plan}

\author{
김준희*・이응직**† \\ Kim Jun-Hui*, Lee Eung-Jik**†
}

(Submit date : 2013. 11. 1., Judgment date : 2013. 11. 5., Publication decide date : 2013. 12. 26.)

\begin{abstract}
At the moment, in Korea, over 90\% of energy resources depend on imports, and nearly 60\% of electric energy is produced using fossil fuel. Therefore, the government adopted the Climatic Change Convention and has implemented the RPS system since 2012 to actively cope with the dependence on imported energy, and to grow and expand the new renewable energy industry. This study examined the performance results of mandatory supply of solar photovoltaic energy and non-solar photovoltaic energy assigned to providers and the present state after implementation of the RPS system. As a result, the achievement rate in 2012 was $64.7 \%$. Especially, solar photovoltaic energy showed a high achievement rate of $95.7 \%$, whereas non-solar photovoltaic energy showed a low achievement rate of $63.3 \%$ due to several problems and was highly dependent on the government. In 2013, the burden of each provider has increased due to more mandatory supply and addition of unfulfilled supply of 2012, and the separate mandatory supply of solar photovoltaic energy established for protection of the solar photovoltaic market is restricting investment. Therefore, there is a need to assign mandatory supply in consideration of the available amount of each new renewable energy.
\end{abstract}

Key Words : RPS(Renewable Portfolio Standard), 신 · 재생에너지(New Renewable Energy), 태양광(Solar Photovoltaic), 비태양광(Non-Solar Photovoltaic)

**† 이응직(교신저자) : 세명대학교 건설공학과 부교수

E-mail : drlee@semyung.ac.kr, Tel :043

*김준희 : 세명대학교 건설공학과 석사과정
**† Lee Eung-Jik(corresponding author) : Department of Architectural, Semyung University.

E-mail : drlee@semyung.ac.kr, Tel : 043

*Kim Jun-Hui : Department of Architecture, Graduate School, Semyung University 


\section{1. 서 론}

현재 인류는 화석연료 사용으로 온실가스 배출에 따른 심각한 이상기후와 환경오염, 매 장량 한계로 인한 에너지 자원 고갈 등의 여러 문제에 직면하고 있다. 특히 우리나라는 에너 지 자원의 $90 \%$ 이상을 수입에 의존하고 전기 에너지의 경우에는 $60 \%$ 를 화석연료를 이용하 여 생산하고 있어 문제의 심각성이 더욱 높다.

이에 정부는 기후변화 협약의 발효와 에너 지 해외의존에 능동적으로 대응하고자 환경 친화적이고 무제한 공급이 가능한 신·재생에 너지 산업의 육성과 발전을 위하여 신·재생에 너지 연구개발 및 보급정책 등을 추진해오고 있다.

2011년까지는 신·재생에너지 발전에 의하 여 공급한 전기의 전력거래가격이 지식경제부 장관이 고시한 기준가격보다 낮은 경우 그 차 액을 지원해주는 발전차액지원제도(Feed-In Tariff, FIT) 중심으로 신·재생에너지 산업을 성장시키고 확대·보급하였다. 그러나 정부의 재정적 부담이 커져 예산상의 제약이 발생하 고 정부 지원 의존도가 높아지면서 기술개발 촉진 기능이 미흡해지는 문제 등으로 2012년 부터는 시장원리에 따른 기업 간의 경쟁을 통해 산 업 성장 및 확대·보급이 이루어질 수 있는 신·재생 에너지 공급의무화제도 (Renewable Portfolio Standard, RPS)를 도입하였고, 아울러 정부 지원 의존도가 높았던 태양광발전의 경우에는 보급·확대와 자생력을 키우기 위해 별도의 의 무공급량을 고시하고 있다.

본 연구에서는 2012년부터 실시한 RPS제도 와 관련된 문헌 및 자료조사, 기관 문의를 통 하여 RPS제도 시행 이후 공급의무자에게 할 당된 의무공급량의 이행 실적 및 현황을 태양 광과 비태양광 부분으로 나누어 조사하였다.
이에 환경친화적 에너지의 보급·확대를 바탕 으로 온실가스 감축과 국가경제의 지속적인 발전을 목표로 한 RPS제도가 원활히 진행되 고 있는지를 파악하고 제도 시행 전에는 미처 예상치 못했던 문제들이나 진행과정에서 발견 된 어려움을 분석하여 제도가 추구하는 본 방 향의 안착을 위한 방향제시에 목적을 둔다.

\section{RPS(Renewable Portfolio Standard)제 도}

\section{$2.1 \mathrm{RPS}$ 제도의 정의}

RPS(Renewable Portfolio Standard)제도는 발전사업자로 하여금 자신의 총발전량의 일정 비율 이상을 신·재생에너지전력으로 공급하도록 의무수준을 할당하는 신·재생에너지 보급제도 이다. 그리고 각 사업자에게 신·재생에너지원으 로부터 공급한 전력량만큼의 REC(Renewable Energy Certificate, 신·재생에너지공급인증서)를 주어, 의무수준 초과분만큼의 $\mathrm{REC}$ 를 의무수 준 달성에 미달한 사업자에게 판매할 수 있다.

\section{$2.2 \mathrm{RPS}$ 제도의 공급의무자 및 의무공급량} RPS제도의 공급의무자는 신·재생에너지 설비를 제외한 설비 규모 50 만 $\mathrm{kW}$ 이상의 발전 사업자인 발전자회사 6 개, 한국수력원자력, 한 국남동발전, 한국중부발전, 한국서부발전, 한 국남부발전, 한국동서발전과 민간발전사 5 개, 포스코 에너지, $\mathrm{SK} \mathrm{E} \& \mathrm{~S}, \mathrm{GS} \mathrm{EPS}, \mathrm{GS}$ 파워, $\mathrm{MPC}$ 율촌 및 공공기관 2개, 한국수자원공사, 한국지역난방공사 총 13 개이다.

의무공급량은 총 발전량에 연도별로 정해진 의무비율 이상을 발전하는 것을 의미하며 2012년 의무비율 $2.0 \%$ 를 시작으로 2015 년까지는 $0.5 \%$ 씩 증가하고 2022 년까지 $1 \%$ 씩 증가하여 $10 \%$ 에 도달할 계획이다. 
Table 1. Proportion of mandatory supply by year

\begin{tabular}{l|l|l|l|l|l|l}
\hline Year & 2012 & 2013 & 2014 & 2015 & 2016 & 2017 \\
\hline $\begin{array}{l}\text { Duty } \\
\text { Rate }\end{array}$ & $2.0 \%$ & $2.5 \%$ & $3.0 \%$ & $3.5 \%$ & $4.0 \%$ & $5.0 \%$ \\
\hline Year & 2018 & 2019 & 2020 & 2011 & 2012 이후 \\
\hline $\begin{array}{l}\text { Duty } \\
\text { Rate }\end{array}$ & $6.0 \%$ & $7.0 \%$ & $8.0 \%$ & $9.0 \%$ & $10.0 \%$ & \\
\hline
\end{tabular}

Table 2. Certificate-weighted enforcement plan

\begin{tabular}{|c|c|c|c|c|}
\hline \multirow[b]{2}{*}{ Division } & \multirow{2}{*}{\begin{tabular}{l|} 
Supply \\
Certificate \\
Weighted \\
value
\end{tabular}} & \multicolumn{3}{|c|}{ Target energy and criteria } \\
\hline & & $\begin{array}{l}\text { Types of } \\
\text { installation }\end{array}$ & $\begin{array}{l}\text { Types of land } \\
\text { category }\end{array}$ & $\begin{array}{l}\text { Volume } \\
\text { criteria }\end{array}$ \\
\hline \multirow{5}{*}{$\begin{array}{l}\text { Solar } \\
\text { photov } \\
\text { oltaic } \\
\text { energy }\end{array}$} & 0.7 & \multirow{4}{*}{$\begin{array}{l}\text { When existing } \\
\text { facilities } \\
\text { including } \\
\text { buildings are } \\
\text { not used. }\end{array}$} & \multicolumn{2}{|c|}{$\begin{array}{l}5 \text { land categories } \\
\text { (field, paddy, orchard, ranch, } \\
\text { forest land) }\end{array}$} \\
\hline & 1.0 & & \multirow{3}{*}{$\begin{array}{l}\text { Other } 23 \text { land } \\
\text { categories }\end{array}$} & Above \\
\hline & \multirow[b]{2}{*}{1.2} & & & $30 \mathrm{~kW}$ \\
\hline & & & & $\begin{array}{l}\text { Below } \\
30 \mathrm{~kW}\end{array}$ \\
\hline & 1.5 & $\begin{array}{l}\text {-When existing } \\
\text { are used. } \\
\text {-When floating } \\
\end{array}$ & $\begin{array}{l}\text { facilities includir } \\
\text { facilities are inste }\end{array}$ & $\begin{array}{l}\text { g buildings } \\
\text { led. }\end{array}$ \\
\hline \multirow{5}{*}{$\begin{array}{l}\text { Other } \\
\text { new } \\
\text { renew } \\
\text { able } \\
\text { energy }\end{array}$} & 0.25 & \multicolumn{3}{|c|}{ IGCC, by-product gas } \\
\hline & 0.5 & \multicolumn{3}{|c|}{ waste, land fill gas } \\
\hline & 1.0 & \multicolumn{3}{|c|}{$\begin{array}{l}\text { water power, onshore wind power, bio-energy, } \\
\text { RDF burning generation, waste gasification } \\
\text { generation, tidal power(sea wall) }\end{array}$} \\
\hline & 1.5 & \multicolumn{3}{|c|}{$\begin{array}{l}\text { wood biomass burning generation, } \\
\text { offshore wind power(interconnection distance: } \\
\text { below } 5 \mathrm{~km})\end{array}$} \\
\hline & 2.0 & \multicolumn{3}{|c|}{$\begin{array}{l}\text { offshore wind power(interconnection distance: } \\
\text { above } 5 \mathrm{~km} \text { ), tidal power(no sea wall), fuel cell }\end{array}$} \\
\hline
\end{tabular}

\section{3 신·재생에너지 공급인증서(REC) 거래제도}

발전사업자가 신·재생에너지설비를 이용하여 전기를 생산·공급하였음을 공급인증기관으로부 터 증명하여 발급받는 인증서가 REC(Renewable Energy CertIficate, 신·재생에너지공급인증서) 이다. REC는 공급인증서의 발급 및 거래단위 로 해당 신·재생에너지설비에서 공급된 $1 \mathrm{MWh}$ 기준의 전력량에 대해 가중치를 곱하여 $1 \mathrm{REC}$ 단위로 발행되며 현재 신·재생에너지원별 공 급인증서 가중치는 환경훼손 최소화, 발전원 가, 온실가스 감축효과, 산업육성효과, 해당
신·재생에너지 부존 잠재량 등을 고려하여 규 정하고 3 년마다 재검토를 통해 고시된다.

현재 인증서 가중치는 태양광 설치 일반 부지의 경우는 $0.7 \sim 1.2$ 인 반면 건축물이용 에 경우 1.5 로 설치 장소에 따라 가중치가 달라지며 기타 신·재생에너지 경우는 연계 거리 $5 \mathrm{~km}$ 초과의 해상풍력과 방조제가 없는 조력, 연료전지가 2.0로 가장 높은 가중치를 가진다.

\section{RPS제도 현황}

\subsection{2년 RPS제도 이행실적 및 현황}

2012년도 RPS제도 신·재생에너지 총 의무 공급량은 642 만279 REC로 목표하였으나 실제 이행한 공급량은 415만 $4227 \mathrm{REC}$ 로 약 $64.7 \%$ 를 달성하였다. 그 중 태양광 부분의 이행 공 급량은 26만 $4180 \mathrm{REC}$ 로 $95.7 \%$ 라는 높은 달성 을 이룬 반면, 비태양광부분은 389만047 REC로 $63.3 \%$ 의 낮은 달성치가 집계되었다.

13 개 발전사별 이행 비율은 $\mathrm{MPC}$ 율촌이 3 만7344 $\mathrm{REC}(100 \%)$ 로 가장 높았고, 다음은 한 국수력원자력이 162 만4616 REC(80.8\%), 한국 지역난방공사 8만3311 $\operatorname{REC}(79.9 \%)$, 한국수자 원공사 1만804 REC(72.6\%), GS파워 5만7023 $\operatorname{REC}(71.3 \%)$, 포스코 에너지 9만9809 $\mathrm{REC}(70 \%)$, 남부발전 56만7046 $\mathrm{REC}(68 \%)$ 등의 순으로 나타났다. 이행 비율이 가장 낮은 곳은 SK $\mathrm{E} \& \mathrm{~S}$ 로 2만 $8835 \mathrm{REC}(34 \%)$ 이며, 한국남동발 전이 36만4391 $\mathrm{REC}(43.7 \%)$ 로 낮은 이행 실적 을 보였다.

이 전체 이행실적 415 만4227 $\operatorname{REC}(64.7 \%)$ 중 자체적으로 이행한 양은 총 172 만 6680 $\mathrm{REC}(26.9 \%)$ 이며 외부구매는 52만7679 $\mathrm{REC}(8.2 \%)$, 국가 $\mathrm{REC}$ 는 189 만9868 $\mathrm{REC}(29.6 \%)$ 로 절반 가량을 국가 $\mathrm{REC}$ 로 충당하였다. 
$\mathrm{RPS}$ 제도 시행에 따른 의무이행 현황 분석 및 개선방안 연구/김준희 외

Table 3. Fulfillment result of each RPS sector in 2012

\begin{tabular}{c|c|c|c|c}
\hline & Fulfillment & $\begin{array}{l}\text { Self-const } \\
\text { ruction }\end{array}$ & $\begin{array}{c}\text { External } \\
\text { Purchase }\end{array}$ & $\begin{array}{c}\text { Governme } \\
\text { nt-REC }\end{array}$ \\
\hline Solar & 264,180 & 63,502 & 195,253 & 5,425 \\
\hline $\begin{array}{l}\text { Non- } \\
\text { solar }\end{array}$ & $3,890,047$ & $1,663,178$ & 332,426 & $1,894,443$ \\
\hline Total & $4,154,227$ & $1,726,680$ & 527,679 & $1,899,868$ \\
\hline
\end{tabular}

$\mathrm{MPC}$ 율촌을 제외한 2012년도 의무공급량 달성하지 못한 12 개의 발전사는 법적으로 최 대 연기 가능한 $30 \%$ 까지는 2013년도로 연기 하였고 남동발전, 중부발전, 서부발전, 남부 발전, 동서발전, $\mathrm{SK} \mathrm{E \& S}$ 는 30\% 초과한 미 이행 부분에 대하여 과징금이 부과되었다. 이는 모두 비태양광에 대한 것이다.
Table 4. The present state of fine imposed on each provider

\begin{tabular}{|c|c|c|c|c|}
\hline & \begin{tabular}{|c|}
$\begin{array}{c}\text { Non-solar } \\
\text { photovoltaic } \\
\text { migration(REC) }\end{array}$ \\
\end{tabular} & \begin{tabular}{|c|} 
Certificate of \\
supply \\
Average \\
transaction \\
price \\
\end{tabular} & $\begin{array}{l}\text { Imposition } \\
\text { rate of fine }\end{array}$ & $\begin{array}{l}\text { Fine } \\
\text { (one } \\
\text { hundred } \\
\text { million) }\end{array}$ \\
\hline $\begin{array}{l}\text { South-East } \\
\text { Power }\end{array}$ & 219,191 & \multirow{6}{*}{$\begin{array}{c}\text { 32,331 } \\
\text { won/REC }\end{array}$} & $150 \%$ & 106.3 \\
\hline $\begin{array}{l}\text { Midland } \\
\text { Power }\end{array}$ & 124,404 & & $120 \%$ & 48.3 \\
\hline $\begin{array}{l}\text { Western } \\
\text { Power }\end{array}$ & 94,179 & & $135 \%$ & 41.1 \\
\hline $\begin{array}{l}\text { Southern } \\
\text { Power }\end{array}$ & 16,685 & & $110 \%$ & 5.9 \\
\hline $\begin{array}{l}\text { East-West } \\
\text { Power }\end{array}$ & 91,158 & & $120 \%$ & 35.4 \\
\hline SK E\&G & 34,272 & & $150 \%$ & 16.6 \\
\hline \multicolumn{4}{|c|}{ Total } & 253.6 \\
\hline
\end{tabular}

Table 5. Fulfillment results of RPS in 2012

\begin{tabular}{|c|c|c|c|c|c|}
\hline Provider & Division & Mandatory supply & Fulfillment & Delay of fulfillment & Non-fulfillment \\
\hline \multirow{3}{*}{$\begin{array}{l}\text { Hydro \& } \\
\text { Nuclear } \\
\text { Power co. }\end{array}$} & Solar & 43,332 & 38,679 & 4,653 & - \\
\hline & Non-solar & $1,966,924$ & $1,585,937$ & 380,987 & - \\
\hline & Subtotal & $2,010,256$ & $1,624,616$ & 385,640 & - \\
\hline \multirow{3}{*}{$\begin{array}{l}\text { South-East } \\
\text { Power }\end{array}$} & Solar & 43,056 & 41,859 & 1,197 & - \\
\hline & Non-solar & 790,632 & 322,532 & 248,909 & 219,191 \\
\hline & 소계 & 833,688 & 364,391 & 250,106 & 219,191 \\
\hline \multirow{3}{*}{$\begin{array}{l}\text { Midland } \\
\text { Power }\end{array}$} & Solar & 43,056 & 42,369 & 687 & - \\
\hline & Non-solar & 695,094 & 349,932 & 220,758 & 124,404 \\
\hline & Subtotal & 738,150 & 392,301 & 221,445 & 124,404 \\
\hline \multirow{3}{*}{$\begin{array}{l}\text { Western } \\
\text { Power }\end{array}$} & Solar & 43,056 & 39,530 & 3,526 & - \\
\hline & Non-solar & 717,647 & 398,784 & 220,758 & 94,179 \\
\hline & Subtotal & 760,703 & 438,314 & 221,445 & 94,179 \\
\hline \multirow{3}{*}{$\begin{array}{l}\text { Southern } \\
\text { Power }\end{array}$} & Solar & 43,056 & 42,797 & 259 & - \\
\hline & Non-solar & 790,845 & 524,249 & 249,911 & 16,685 \\
\hline & Subtotal & 833,901 & 567,046 & 250,170 & 16,685 \\
\hline \multirow{3}{*}{$\begin{array}{l}\text { East-West } \\
\text { Power }\end{array}$} & Solar & 43,056 & 43,056 & - & - \\
\hline & Non-solar & 691,227 & 379,785 & 220,284 & 91,158 \\
\hline & Subtotal & 734,283 & 422,841 & 220,284 & 91,158 \\
\hline \multirow{3}{*}{$\begin{array}{l}\text { District } \\
\text { Heating } \\
\text { Corporation }\end{array}$} & Solar & 2,484 & 2,174 & 310 & - \\
\hline & Non-solar & 101,831 & 81,137 & 20,694 & - \\
\hline & Subtotal & 104,315 & 83,311 & 21,004 & - \\
\hline \multirow{3}{*}{$\begin{array}{l}\text { Water } \\
\text { Resources } \\
\text { corporation }\end{array}$} & Solar & 2,484 & 1,804 & 680 & - \\
\hline & Non-solar & - & - & - & - \\
\hline & Subtotal & 2,484 & 1,804 & 680 & - \\
\hline \multirow{3}{*}{ SK E\&S } & Solar & 2,484 & 2,041 & 443 & - \\
\hline & Non-solar & 87,668 & 26,794 & 26,602 & 34,272 \\
\hline & Subtotal & 90,152 & 28,835 & 27,045 & 34,272 \\
\hline \multirow{3}{*}{ GS EPS } & Solar & 2,484 & 2,484 & - & - \\
\hline & Non-solar & 78,637 & 54,539 & 24,098 & - \\
\hline & Subtotal & 81,121 & 57,023 & 24,098 & - \\
\hline \multirow{3}{*}{ GS Power } & Solar & 2,484 & 2,419 & 65 & - \\
\hline & Non-solar & 140,099 & 34,173 & 14,642 & - \\
\hline & Subtotal & 51,299 & 36,592 & 14,707 & - \\
\hline \multirow{3}{*}{$\begin{array}{l}\text { Posco } \\
\text { Energy }\end{array}$} & Solar & 2,484 & 2,484 & - & - \\
\hline & Non-solar & 140,099 & 97,325 & 42,774 & - \\
\hline & Subtotal & 142,583 & 99,809 & 42,774 & - \\
\hline \multirow{3}{*}{$\mathrm{MPC}$ 율촌 } & Solar & 2,484 & 2,484 & - & - \\
\hline & Non-solar & 34,860 & 34,860 & - & $\begin{array}{l}- \\
-\end{array}$ \\
\hline & Subtotal & 37,344 & 37,344 & - & - \\
\hline \multirow{3}{*}{ Total } & Solar & 276,000 & 264,180 & 11,820 & - \\
\hline & Non-solar & $6,144,279$ & $3,890,047$ & $1,674,343$ & 579,889 \\
\hline & Subtotal & $6,420,279$ & $4,154,227$ & $1,686,163$ & 579,889 \\
\hline
\end{tabular}


과징금 규모는 불이행량에 해당연도 공급인 증서 평균거래가격을 곱하여 산정한 후, 가중 및 감경사유를 가감해서 최종 결정된다. 2012년 비태양광 평균거래가격은 3만2331원/REC이며 의무공급량 불이행한 6 개사업자에 대한 과징금 은 총 253억6000만원이다. 이는 과징금 상한선 278 억원에 비해 약 $9.8 \%$ 가량 감경된 금액이다.

\subsection{3년 RPS제도 의무공급량}

2013년도 의무공급량 비율은 총 발전량에 $2.5 \%$ 로 13 개 발전사의 총 의무공급량은 921 만381 MWh이며 태양광 별도 의무공급량은 72만3,000 MWh이다. 이는 2012년도 총 의무 공급량인 642 만 $279 \mathrm{MWh}$ 대비 $43 \%$ 가량 증가 한 것이며, 태양광 별도 의무공급량은 지난해 27 만6,000 MWh에 비해 약 2.7배 증가하였다.

Table 6. Separate mandatory supply of solar photovoltaic energy

\begin{tabular}{l|l|l|l|l}
\multicolumn{5}{|c}{ (Unit:GWh) } \\
\hline Year & 2012 & 2013 & 2014 & 2015 after \\
\hline $\begin{array}{l}\text { Mandatory } \\
\text { supply }\end{array}$ & 276 & 723 & 1,156 & 1,577 \\
\hline
\end{tabular}

태양광의 경우 2012년 계획했던 의무공급량 보다 높은 의무공급량이 책정되었는데, 이는 세계경제 침체 등으로 국내 태양광 에너지산 업이 위축됨에 따라 단기간 내수시장을 확보 하기 위하여 2015 년 $1.2 \mathrm{GW}$ 달성목표를 $1.5 \mathrm{GW}$ 로 확대 변경하면서 연도별 태양광 별 도 의무공급량도 증가 조정되었기 때문이다.

또한 태양광 설치 촉진 및 태양광 소규모 발전 사업자 보호를 위하여 $5 \mathrm{GW}$ 이상의 발전 설비를 보유한 공급의무자는 $5 \mathrm{GW}$ 이상의 발 전 설비를 보유한 공급의무자가 아닌 사업자 로부터 별도 의무공급량의 $50 \%$ 이상을 구매하 여 충당하여야 한다는 규정이 만들어졌다.
Table 7. Mandatory supply assigned to each provider in 2013

\begin{tabular}{c|c|c|c}
\hline \multicolumn{2}{c}{ Division } & $\begin{array}{c}\text { Total } \\
\text { mandatory } \\
\text { supply }\end{array}$ & $\begin{array}{c}\text { Separate } \\
\text { mandatory } \\
\text { supply of } \\
\text { solar energy }\end{array}$ \\
\hline \multirow{4}{*}{$\begin{array}{c}\text { Group } \\
\text { I }\end{array}$} & $\begin{array}{c}\text { Hydro \& Nuclear } \\
\text { Power co. }\end{array}$ & $2,462,729$ & 114,234 \\
\cline { 2 - 4 } & South-East Power & $1,267,213$ & 110,619 \\
\cline { 2 - 4 } & Midland Power & $1,055,337$ & 110,619 \\
\cline { 2 - 4 } & Western Power & $1,140,889$ & 110,619 \\
\cline { 2 - 4 } & Southern Power & $1,285,500$ & 110,619 \\
\cline { 2 - 4 } & East-West Power & $1,156,946$ & 110,619 \\
\hline \multirow{4}{*}{$\begin{array}{c}\text { District Heating } \\
\text { Corporation }\end{array}$} & 164,354 & 7,953 \\
\cline { 2 - 4 } & $\begin{array}{c}\text { Water Resources } \\
\text { corporation }\end{array}$ & 7,953 & 7,953 \\
\cline { 2 - 4 } & SK E\&S & 125,974 & 7,953 \\
\cline { 2 - 4 } & GS EPS & 131,999 & 7,953 \\
\cline { 2 - 4 } & GS Power & 91,364 & 7,953 \\
\cline { 2 - 4 } & Posco Energy & 260,850 & 7,953 \\
\cline { 2 - 4 } & MPC(율촌) & 59,273 & 7,953 \\
\hline & Total & $9,210,381$ & 723,000 \\
\hline
\end{tabular}

\subsection{RPS제도 현황파악 및 문제점 분석}

지난 2012년 RPS 의무이행 비율은 $64.7 \%$ 로 다소 저조한 성과를 거두었으며 이에 미이행 부분에 대한 과징금 또한 총 253억 6000만원 이라는 큰 금액이 부과되었다. 그리고 태양광 과 비태양광 사이에 상당한 이행비율 차이가 나타나는 것을 보면 비태양광 의무공급량 이 행에 있어 많은 어려움을 예측할 수 있다. $\mathrm{RPS}$ 제도 시행 2 년차인 올해 이행목표는 총 발전량에 의무비율 $2.5 \%$ 로 더욱 증가하였고 지난 해 미이행 부분에 대한 물량까지 더해져 악순환이 반복될 것으로 판단된다.

태양광과 비태양광의 상이한 이행실적은 현재 의무공급물량이 현실적인 보급여건과 맞 지 않아 생긴 문제라고 분석된다. 즉 환경부의 규제와 각종 인허가 문제 등으로 수력, 풍력, 조력 등 비태양광 부분의 사업추진이 원활하 
지 못하고 해당지역의 다양한 민원도 계획한 투자를 제대로 실행할 수 없는 요인으로 작용 했다. 지난해 한수원의 경우도 $1,320 \mathrm{MW}$ 규모 의 인천만 조력발전사업을 계획했으나 인·허 가 단계에서 좌초됨에 따라 의무공급량을 이 행하는데 중대한 차질이 발생했고 이를 만회 하기 위해 풍력, 연료전지 사업을 추진했지만 재생에너지 자원이 한정된 상황에서 목표 달 성이 쉽지 않다는 분석이 있었다. 그러나 의무 공급량 달성을 위해 생태계를 파괴하는 대규 모 발전소 건설을 무조건 묵인할 수도 없는 문제이다.

앞서 언급한 바와 같이 현실과 맞지 않는 의무공급량은 할당량을 채우는데 급급한 현상 을 초래할 우려가 있으며 환경 보전의 목적을 잊고 대규모 발전소 건설에만 집중될 수 있다. 또한 의무불이행 시 과징금의 부담이 있기 때 문에 경제성이나 환경적 영향에 대한 고려보 다는 대규모 발전을 통해 의무할당량 채우기 에 초점을 맞추는 현상이 발생할 수 있다.

지난해 의무이행실적인 642 만 $279 \mathrm{REC}$ 중 자체건설을 통한 이행은 172 만 $6680 \mathrm{REC}$ (26.9\%) 로 절반도 되지 않았다. 특히 비태양광 부분의 경우 총 이행물량인 389만 $47 \mathrm{REC}$ 중 국가가 보유한 REC 구매를 통해 의무이행량 절반에 가까운 189 만 $4443 \operatorname{REC}(30.8 \%)$ 를 채웠다. 태 양광의 경우 국가 $\mathrm{REC}$ 구매가 $2 \%$ 에 불과했 다는 것과 비교해보면 비태양광 부분의 정부 의존 현상이 상당하다는 것을 알 수 있다. 비 태양광의 경우 이행실적도 $63.3 \%$ 의 저조한 결과를 보였는데 이행실적의 절반을 국가에 의존하여 충당한 것이다. 매년 의무할당량 비 율은 증가하고 반대로 이월할 수 있는 물량은 낮아지기 때문에 자체발전량을 늘리지 않으면 향후 의무공급량 달성은 더욱 어려워 질 것으 로 판단된다.
당초 RPS제도 시행 전 태양광의 발전단가 가 높아 별도의 의무할당량을 설정했지만 예 상과는 달리 현재 태양광이 비태양광에 비해 공급여력이 더 많은 상황이며 태양광 시장 보 호를 위해 마련한 별도 의무공급량이 오히려 투자 제약 요건으로 작용되고 있는 실정이다.

\section{4. 제언 및 결론}

현재 RPS제도의 전체 이행실적을 보면 $64.7 \%$ 로 절반을 조금 넘는 다소 낮은 이행 실적을 보였고 그 결과 미이행 물량의 이월로 인한 의무이행 과중이라는 부분과 과징금 부과, 현 실의 보급여건과 맞지 않은 의무공급량으로 태양광과 비태양광의 상이한 이행실적 등의 문제점이 분석되었다.

태양광 시장 보호를 위해 설정한 태양광 별 도 의무공급량은 오히려 태양광 산업 발전에 제약 요건으로 작용했고, 조력이나 수력 등의 대규모 발전소 건설은 단순히 에너지를 발전 할 때 이산화탄소 배출이 없다는 이유로 발전 소 건설에 따른 환경파괴 정도나 경제성을 간 과할 있다는 우려가 따랐다. 따라서 가장 큰 비중을 차지하는 비태양광부분의 이행 달성의 어려움을 묵인한 채 태양광과 비태양광으로 나누어 의무공급량을 책정하는 것에 대한 수 정이 필요하다.

다시 말해 의무공급량을 태양광, 비태양광 으로 구분하여 책정하기 보다는 에너지원별 특성과 환경에 미치는 요인, 기술개발의 현황, 향후 발전가능성 및 경제성 등을 종합적으로 분석하여 신·재생에너지원별로 발전 가능한 양 할당함이 바람직하다고 사료된다.

무엇보다 기존 건축물에 적용하는 태양광발 전은 부가적 설치면적을 필요로 하지 않고 또 발전하는 곳과 소비하는 곳이 동일 위치에 존 
재한다는 장점으로 1.5 의 가중치를 부여하는 상황이므로 학교의 옥상 등을 적극 활용 할 수 있는 법적근거 마련도 필요한 시기라고 판 단된다.

\section{참 고 문 헌}

1. Sin Seongryoung, A study of policies for the development of renewable portfolio standards (RPS), Master Dissertation, The Graduate Schoo of KwangWoon University, 2011

2. No Sangyang, The present state and direction of domestic RPS system, The Korean Institute of Electrical Engineers, Vol .59 No. 12, 18p 21p, 2010

3. So Byeonguk, A Study on analysis photovoltaic business under Renewable Portfolio Standard (RPS), Master Dissertation, ChonBuk, National University, 2012

4. A guide for mandatory supply of new and renewable energy(RPS), Ministry of Trade, Industry \& Energy, Korea Energy Management Corporation, 2013

5. www.energy.or.kr

6. www.motie.go.kr 